\title{
Traumatic brain injury: simple data collection will improve the outcome
}

Severe and moderate traumatic brain injury (TBI) constitutes a major health and socio-economic problem throughout the world [1]. In the US, approximately 2 million injuries occur each year resulting in 56.000 deaths and 18.000 survivors suffering from permanent neurological impairment [2-4]. The consequent direct and indirect annual costs in the US are estimated at $\$ 56$ billion [5].

TBI is the leading cause of death and disability among young adults in developed countries and the incidence in the elderly population is increasing [6,7]. In less developed countries the incidence of TBI is high and rapidly increasing. The WHO has projected that by the year 2020 road traffic accidents, a major cause of TBI will rank third as a leading cause of the global burden of disease and injury behind only ischemic heart disease and unipolar major depression [8]. There is therefore a strong ethical imperative to enhance TBI prevention and to improve treatment. TBI is a field in medicine with one of the greatest unmet needs.

Yet, funding for head injury research is low.

Appropriate targeting of prevention and improving outcome requires a detailed understanding of incidence, causes of injury, treatment approaches and outcome results. Complicating factors are that TBI is not one single disease entity, but includes a vastly heterogeneous and complex spectrum of pathology ranging from diffuse axonal injury and focal contusions to extracerebral hematoma. TBI populations are also extremely heterogeneous in terms of clinical severity and baseline prognostic risk with many patients also suffering from extracranial injuries and secondary insults (e.g. hypoxia and/or hypotension). Further, considerable variation exists in baseline clinical management, and the sequence of treatment strategies deployed may vary considerably between centers and countries. Consequently, observational studies are necessary to accurately characterize treatment approaches on international, national and local levels. Much can be learned from observational studies. Previous observational studies on an international level include the Traumatic Coma Databank [9] and the Core Data Survey of the European Brain Injury Consortium [10] and on a national level the UK Four Center study [11] and studies by the Trauma Audit and Research Network in the UK (www. tarn.ac.uk). Much of the advances in TBI care achieved over the past decades have resulted from these studies. The TCDB was instrumental in demonstrating adverse consequences of secondary insults and a landmark paper on behalf of the TARN network [12] showed a 2.15 fold increase in the odds of death adjusted for case mix for patients with severe TBI treated in non-neurosurgical center compared to those treated at a neurosurgical center. This paper makes a strong case for transferring and treating all patients with severe head injury in a setting with 24 hours neurosurgical facilities.

Substantial differences may exist in trauma organization, treatment and outcome of TBI patients [13] and consequently observational studies on a national level are of great relevance. The manuscripts in this issue of the Wiener Klinische Wochenschrift on the Austrian Severe Traumatic Brain Injury study present a comprehensive overview of the current state of the art in Austrian head injury centers and set an example which should be followed by many other countries within and outside the European Union [14-19]. Participating in an observational study may in itself promote quality of care. Sir Graham Teasdale, one of the world leaders in the field of TBI, asked if he would ever personally consent to participation in a clinical trial on TBI once answered that he certainly would, but would wish to be allocated to the placebo group. This reflects the understanding that patients allocated to a placebo group within a trial may benefit from closer scrutiny of their clinical course and better adherence to guidelines whilst not being exposed to any additional risk of an investigational treatment. Similar benefits apply to observational studies. Observational studies however suffer from a number of limitations, not in the least part caused by relative lack of funding. Such limitations are also evident in the Austrian severe traumatic brain injury study. The original intent was to collect data from 10 Austrian centers, but data collection was limited to 7 due to financial restrictions, and of these 2 were dropped from the study early on. Missing values are a common problem in medical research in general, particularly if they concern outcome results. Overall, the number of missing values for demographic data and important predictors in this study was low $(<5 \%)$, but outcome at 360 days was missing in $28 \%$ of patients. Imputation of outcome was performed according to the last value carried forward procedures, imputing where available the 3 and 6 month outcomes. Following imputation outcome remained missing in $16 \%$. For an observational study this may be considered fairly good. The outcome distribution in the series is reported with a separate category for the missing outcomes resulting in an overall mortality of $38 \%$. This mortality percentage can be considered accurate as most missing values for outcome will have been in survivors and is comparable to mortality 
rates in the prospective TCDB, UK4 and EBIC studies (36-40\%). On comparison of various characteristics observed during the Austrian data collection to previous prospective series (Table 1) various interesting observations can be noted.

The percentage of primary admissions is much higher in the Austrian study than in previous prospective series, reflecting an appropriate trauma organization. The increase of average age over time is remarkable and probably reflects a combination of effects an ageing population and the success of preventive measures in terms of road traffic safety, reducing the number of severe TBI particularly in young adult males. The increase in average age may however also indicate an absolute increase in TBI in the elderly population as has been observed in studies from Finland $[6,7]$. The high percentage of falls observed is consistent with the higher average age of the Austrian TBI population as a clear relation between falls as cause of injury and higher age has been demonstrated [20]. These data indicate a desire to target the elderly population in prevention campaigns. The high percentage of patients undergoing intracranial surgery is also consistent with a higher age and greater number of falls as cause of injury, as both these factors are related to an increased number of mass lesions [21]. A specific aspect, not investigated in this study is whether the increased use of anticoagulant medication, especially in elderly patients, may pre-dispose to the development of more intracranial complications in this population. In general, the presence of coagulopathy following TBI and effects of pre-trauma anti-coagulant medication should be a focus for future research in TBI.

Comparing outcome results between different series of patients with TBI and comparing observed outcomes versus expected outcomes as performed in the Austrian study and reported extensively in manuscripts III-V is a complex issue in view of the existing heterogeneity. In the Austrian study, expected mortality was calculated by using the TRISS methodology. It may be doubted whether this approach is appropriate. First, the TRISS method was published in 1987 and secondly this methodology was primarily focused on evaluation of general trauma care and not specifically towards TBI. In my opinion there is a great need for well validated disease specific prognostic models for TBI such as published by Hukkelhoven et al. [22]. Such models are a pre-requisite for comparing different populations, and may serve as a tool for quality control in assessment of outcome results. Much work is required in order to demonstrate generalizability and validity of such models across series obtained in different settings. Given the limitations of the TRISS methodology, interpretation of results should be with caution.

Various interesting associations between baseline predictors, treatment approaches and outcome are reported, but conclusions in regard to therapeutic implications can not always be drawn from an observational study. As an example, in manuscript IV on intensive care management a clear association between hyperglycemia and poorer outcome was noted and the conclusion drawn that insulin may improve the outcome after sever TBI. A recent meta analysis on data from 4834 patients with TBI found a continuous relation between glucose levels and outcome in TBI [23]. These findings and the observed relation between higher glucose levels and poorer outcomes in the Austrian study are certainly interesting, but should rather be considered as hypothesis generating to further explore benefits of interventions aimed at decreasing hyperglycemia than as direct causal relation with therapeutic implications. To our knowledge no studies have directly addressed the benefits of more intensive management of hyperglycemia in TBI, but in general critical care medicine a reduction of ICU mortality has been found with more intensive management of hyperglycemia [24]. Extrapolation of these results towards TBI may be appropriate but requires further studies. Particular care will however be required to prevent insulin overdose and subsequent hypoglycemia as this may have even more detrimental effect on the injured brain.

The original intent of the Austrian severe traumatic brain injury study was to assess the effect of implementation of guidelines for TBI on outcome. In practice, this could not be accomplished as on initiation of the study, various recommendations from the TBI guidelines had already been implemented in centers. The innovative approach taken by the investigators and reported in manuscript VI, assessing the effects of adherence to guidelines on outcome may be considered original and stimulating.

Table 1. Characteristics of Austrian severe TBI study compared to other prospective surveys

\begin{tabular}{lllll}
\hline Study & TCDB & UK 4 & EBIC severe & Austria \\
\hline Year of study & $1984-1987$ & $1986-1988$ & 1995 & $1999-2004$ \\
Sample size & 746 & 988 & 583 & 492 \\
Direct admission to NTC & $61 \%$ & $12 \%$ & $45 \%$ & $85 \%{ }^{\mathrm{a}}$ \\
Age: & & & $41 \pm 20$ & $48 \pm 21$ \\
$\quad$ Mean \pm SD & $25^{\mathrm{b}}$ & $34 \pm 21$ & $2-92$ & $0-102$ \\
$\quad$ Range & $0-93$ & $0-87$ & $73 \%$ & $72 \%$ \\
Male & $77 \%$ & $75 \%$ & $22 \%$ & $41 \%$ \\
Percentage falls & $16 \%$ & $25 \%$ & $37 \%$ & $56 \%$ \\
Percentage intracranial surgery & $33 \%$ & $39 \%$ & $40 \%$ & $38 \%$ \\
Mortality $^{c}$ & $36 \%$ & $39 \%$ & & \\
\hline
\end{tabular}

${ }^{\mathrm{a}} \mathrm{n}=396$; ${ }^{\mathrm{b}}$ median age; ${ }^{\mathrm{c}}$ outcome assessed at 6 months for TCDB, UK4 and EBIC; at 12 months for Austrian study. 
Further research is however required to define and validate this approach.

Although the original goal of the study could not be accomplished, the overall achievements are impressive, for which the contributing investigators and coordinating study personnel should be congratulated. The current standards of care have been set, areas for improvement identified and exciting hypothesis generated for future studies. Most importantly, many of the results support the importance of guideline implementation and adherence. These achievements highlight how simple data collection has the potential to improve outcome in traumatic brain injury.

Andrew I. R. Maas

\section{References}

1. Ghajar J (2000) Traumatic brain injury. Lancet 356: $923-$ 929

2. Sosin DM, Sniezek JE, Thurman DJ (1996) Incidence of mild and moderate brain injury in the United States, 1991. Brain Inj 10: 47-54

3. Kraus JF, McArthur DL (1996) Epidemiologic aspects of brain injury. Neurol Clin 14: 435-450

4. Bruns J jr, Hauser WA (2003) The epidemiology of traumatic brain injury: a review. Epilepsia 44 [Suppl 10]: $2-$ 10

5. Thurman DJ, Alverson C, Dunn KA, et al (1999) Traumatic brain injury in the United States: a public health perspective. J Head Trauma Rehabil 14: 602-615

6. Kannus P, Palvanen M, Niemi S (1999) Increasing number and incidence of fall-induced severe head injuries in older adults: nationwide statistics in Finland in 1970-1995 and prediction for the future. Am J Epidemiol 149 (2): 143150

7. Luukinen H, Herala M, Koski K, Kivela SL, Honkanen R (1999) Rapid increase of fall-related severe head injuries with age among older people: a population-based study. J Am Geriatr Soc 47 (12): 1451-1452

8. Finfer SR, Cohen J (2001) Severe traumatic brain injury. Resuscitation 48: 77-90

9. Foulkes AM, Eisenberg MH, Jane AJ (1991) The traumatic coma data bank: design, methods, and baseline characteristics. J Neurosurgery 75: s8-s15

10. Murray GD, Teasdale GM, Braakman R, et al (1999) The European Brain Injury Consortium survey of head injuries. (1999). Acta Neurochir (Wien) 141 (3): 223-236

11. Murray LS, Teasdale GM, Murray GD, et al (1999) Head injuries in four British neurosurgical centres. Br J Neurosurg 13 (6): 564-569

12. Patel HC, Bouamra O, Woodfort M (2005) Trends in head injury outcome from 1989 to 2003 and the effect of neurosurgical care: an observational study. The Lancet 366: $1538-1544$
13. Hukkelhoven CW, Steyerberg EW, Farace E, et al (2002) Regional differences in patient characteristics, case management, and outcomes in traumatic brain injury: experience from the Tirilazad trials. J Neurosurg 97 (3): 549557

14. Rusnak M, Janciak I, Majdan M, Wilbacher I, Mauritz W, for the Austrian Severe TBI Study Investigators (2007) Severe traumatic brain injury in Austria I: introduction to the study. Wien Klin Wochenschr 119: 23-28

15. Rosso A, Brazinova A, Janciak I, Wilbacher I, Rusnak M, Mauritz W; for the Austrian Severe TBI Study Investigators (2007) Severe traumatic brain injury in Austria II: epidemiology of hospital admissions

16. Lenartova L, Janciak I, Wilbacher I, Rusnak M, Mauritz W; for the Austrian Severe TBI Study Investigators (2007) Severe traumatic brain injury in Austria III: prehospital status and treatment. Wien Klin Wochenschr 119: 35-45

17. Mauritz W, Janciak I, Wilbacher I, Rusnak M, for the Austrian Severe TBI Study Investigators (2007) Severe traumatic brain injury in Austria IV: intensive care management. Wien Klin Wochenschr 119: 46-55

18. Leitgeb J, Erb K, Mauritz W, Janciak I, Wilbacher I, Rusnak M; for the Austrian Severe TBI Study Investigators (2007) Severe traumatic brain injury in Austria V: CT findings and surgical management. Wien Klin Wochenschr 119: $56-63$

19. Rusnak M, Janciak I, Majdan M, Wilbacher I, Mauritz M; for the Austrian Severe TBI Study Investigators (2007) Severe traumatic brain injury in Austria VI: effects of guidelinebased management. Wien Klin Wochenschr 119: 64-71

20. Butcher I, McHugh GS, Lu J, et al (2007) The prognostic value of cause of injury in traumatic brain injury: results from the IMPACT study. J Neurotrauma (in press)

21. Maas AIR, Steyerberg EW, Butcher I, et al (2007) The prognostic value of computerized tomography scan characteristcs in traumatic brain injury: results from the IMPACT study. J Neurotrauma (in press)

22. Hukkelhoven CW, Steyerberg EW, Habbema DF (2005) Predicting outcome after traumatic brain injury: development and validation of a prognostic score based on admission characteristics. J Neurotrauma 22: 1025-1039

23. Van Beek J, Mushkudiani NA, Steyerberg EW, et al (2007) The prognostic value of admission laboratory parameters in traumatic brain injury. J Neurotrauma (in press)

24. Van den Berghe G, Wouters P, Weekers F, et al (2001) Intensive insulin therapy in the critically ill patients. $\mathrm{N}$ Engl J Med 345: 1359-1367

Key words: Traumatic brain injury, epidemiology, outcome, classification, prognosis, database.

Correspondence: Andrew I. R. Maas, Department of Neurosurgery, Erasmus MC Rotterdam, The Netherlands, E-mail: airmaas@erasmusmc.nl 